\title{
Efeito tóxico de alimentos alternativos para abelhas Apis mellifera
}

\author{
Toxic effect of alternative feeds for honeybees Apis mellifera
}

\author{
Fábia de Mello Pereira ${ }^{\mathrm{I}}$ Breno Magalhães Freitas ${ }^{\mathrm{II}}$ José Maria Vieira Neto ${ }^{\mathrm{III}}$ \\ Maria Teresa do Rêgo Lopes ${ }^{\text {III }}$ Alessandra de Lima Barbosa ${ }^{\text {III }}$ \\ Ricardo Costa Rodrigues de Camargo ${ }^{\text {III }}$ \\ Valdenir Queiroz Ribeiro ${ }^{\text {III }}$ \\ Renato Santos Rocha"II
}

RESUMO

Esta pesquisa foi realizada com o objetivo de avaliar a existência de efeito tóxico em alimentos protéicos alternativos fornecidos para abelhas Apis mellifera. Medindose o tempo médio de mortalidade e o índice de mortalidade de abelhas confinadas, avaliou-se a existência de efeito tóxico do: (a) feno das folhas de mandioca (Manihot esculenta); (b) feno das folhas de leucena (Leucaena leococephala); (c) farinha de vagem de algaroba (Prosopis juliflora); (d) farinha de vagem de bordão-de-velho (Pithecellobium cf. saman); (e) farelo de babaçu (Orbygnia martiana) e ( $f$ ) sucedâneo do leite para bezerros da marca Purina ${ }^{\circledR}$. O tempo médio de mortalidade variou de 4,46 a 11,74 e o índice de mortalidade variou de 4,58 a 12,80. Durante o experimento, obsevou-se que as abelhas alimentadas com farinha de bordão-de-velho ficavam envoltas em uma crosta de alimento, morrendo asfixiadas posteriormente. Os resultados demonstraram que a farinha de bordão-de-velho não deve ser fornecida às abelhas. Não foi observado efeito tóxico nos demais alimentos estudados.

Palavras-chave: Apis mellifera, toxicidade, alimentação alternativa.

\section{ABSTRACT}

The objective of this research was to study toxic effects of alternative feeds for honeybees Apis mellifera. The average mortality time and the mortality index of cagged honeybees were assessed to evaluate any possible toxic effect of: (a) cassava hay (Manihot esculenta); (b) leucaena hay (Leucaena leococephala); (c) mesquite pod meal (Prosopis juliflora); (d) "bordão-de-velho" pod meal (Pithecellobium cf. saman); (e) babassu bran (Orbygnia martiana) and (f) succedaneous for calfskin from Purina ${ }^{\circledR}$. The mortality time average varied from 4.46 to 11.74 and the mortality index varied between 4.58 and 12.80. It was obseved that honeybees fed with "bordão-de-velho" pod meal got involved by stichy layer of food and died asphyxiated. Results showed that the flour of Pithecellobium cf. saman should not be used for feeding honeybees, considering the early mortality of workers fed with this meal. The other food studied did not show any toxic effect.

Key words: Apis mellifera, toxic effect, alternative feeding.

\section{INTRODUÇÃO}

Por ser capaz de aproveitar a mão-de-obra familiar, gerar renda e fixar o homem no campo, aproveitando o potencial da vegetação da Caatinga no semi-árido, a apicultura é uma atividade crescente no Nordeste do Brasil, onde se caracteriza por ser praticada por pequenos apicultores ligados à agricultura familiar. Esses produtores, em geral descapitalizados, não vêem a atividade apícola como uma ocupação principal, mas somente como um complemento da renda (PEREIRA et al., 2000; PEREIRA, 2002).

Apesar do potencial florístico do Nordeste, para a manutenção de uma apicultura produtiva e rentável, torna-se necessário o fornecimento de alimento protéico e energético no período da estiagem (PEREIRA, 1997), que pode se prorrogar por seis a oito meses consecutivos (CEPRO, 1992). A alimentação mantém as colônias populosas, garantindo maior produção na safra seguinte. Sem o fornecimento do

IEmbrapa Meio-Norte, Av. Duque de Caxias, 5650, CP 01, 64006-220, Teresina, PI, Brasil. E-mail: fabia@cpamn.embrapa.br. IIDepartamento de Zootecnia, Universidade Federal do Ceará, Campus do Pici, Fortaleza, CE, Brasil. E-mail: freitas@ufc.br.

IIIEmbrapa Meio-Norte, Teresina, PI, Brasil. 
alimento, além do comprometimento da produção, os apicultores correm o risco de perder suas colônias, que abandonam as colméias em busca de condições ambientais mais favoráveis (FREITAS, 1991; LIMA, 1995).

Segundo SOUSA et al. (2000), o percentual de abandono das colméias na região da Caatinga, causado pela indisponibilidade de néctar e pólen, é de 31,25\%. Devido a essas condições adversas de clima e florada, os apicultores buscam informações com técnicos e pesquisadores sobre opções de alimentos artificiais para minimizar o problema quando necessário. Contudo, a descapitalização dos apicultores, que, em geral, não possuem recursos para adquirir rações comerciais ou outros tipos de alimentos, é um empecilho para esse manejo. Faz-se necessário, assim, o desenvolvimento de uma ração formulada com ingredientes regionais de fácil aquisição ou produção para esses apicultores.

Enquanto não dispõe de uma alternativa satisfatória, os apicultores têm buscado amenizar o problema da estiagem por conta própria, fornecendo às abelhas rapadura de cana-de-açúcar, xarope de água e açúcar, farelo de soja, achocolatado em pó, farinha láctea, ração de postura para galinha, sucedâneo de leite para bezerro e ração de codorna (PEREIRA et al., 2000; PEREIRA, 2002).

Contudo, boa parte desses produtos é ministrada sem que haja um respaldo de pesquisas sobre a viabilidade deste fornecimento e uma análise sobre a existência de um possível efeito tóxico do alimento para as abelhas. HAYDAK (1945) observou que a maioria das larvas dos núcleos de Apis mellifera alimentadas com leite em pó e farinha de soja na proporção de 1:4 morriam antes de 2,5 dias após a eclosão. BARKER (1977) considerou que $40 \%$ dos açúcares contidos na soja são tóxicos para as abelhas e SYLVESTER (1979) verificou que a adição de $10 \%$ de lactose ou galactose em xarope de açúcar reduz a aceitação do alimento e aumenta a mortalidade das abelhas.

Ao fornecer alimento às abelhas sem um prévio conhecimento sobre a existência da toxicidade, o apicultor poderá prejudicar suas atividades, matando suas colônias. Com a intenção de contribuir para evitar esse problema, desenvolveu-se esta pesquisa para avaliar o efeito tóxico de alguns alimentos alternativos fornecidos às abelhas Apis mellifera.

\section{MATERIAL E MÉTODOS}

A pesquisa foi conduzida entre janeiro e agosto de 2003 no Núcleo de Pesquisas com Abelhas
(NUPA) da Embrapa Meio-Norte, Teresina, Piauí, situado a $79 \mathrm{~m}$ de altitude, $5^{\circ} 05^{\prime} \mathrm{S}$ de latitude e $42^{\circ} 49^{\prime} \mathrm{W}$ de longitude (CEPRO, 1992). Foi avaliado o eventual efeito tóxico do feno das folhas de mandioca (Manihot esculenta); do feno das folhas de leucena (Leucaena leococephala); da farinha das vagens de algaroba (Prosopis juliflora); da farinha das vagens de bordãode-velho (Pithecellobium cf. saman); do farelo de babaçu (Orbygnia martiana) e do sucedâneo do leite para bezerros da marca Purina ${ }^{\circledR}$.

Para preparo dos fenos, as folhas de leucena e mandioca tiveram os pecíolos eliminados, foram colocadas para secar à sombra por $24 \mathrm{~h}$ e, em seguida, levadas à estufa de ventilação forçada a $60^{\circ} \mathrm{C}$, onde permaneceram por mais $24 \mathrm{~h}$. Após esse tempo, as folhas foram processadas em um moinho modelo Willye e passadas em uma peneira com granulometria de $2 \mathrm{~mm}$.

O processamento das vagens e do farelo de babaçu ocorreu de forma semelhante; entretanto, esses alimentos necessitaram permanecer na estufa por $72 \mathrm{~h}$ ou até que estivessem suficientemente secos. O sucedâneo do leite da marca Purina ${ }^{\circledR}$ encontrado em locais que comercializam ração para gado já é finamente moído e não exige processamento.

O efeito tóxico dos alimentos foi caracterizado pela mensuração do índice de mortalidade (IM) e do tempo médio de mortalidade (TMM) das abelhas confinadas e que receberam alimentação controlada. Para essa avaliação, colocou-se em uma estufa quadros de cria de Apis mellifera contendo pupas prestes a nascer. A temperatura interna da estufa e a umidade relativa foram controladas para $34^{\circ} \mathrm{C}$ e $67 \%$, respectivamente. Logo após a emergência, as operárias foram coletadas e confinadas em gaiolas de madeira semelhantes às usadas por KULENCEVIC \& ROTHENBUHLER (1972), possuindo dimensão de $8 \mathrm{x}$ 11 x $13 \mathrm{~cm}$, duas laterais de vidro e piso telado. Cada gaiola recebeu cerca de 50 operárias que tiveram à sua disposição mel, água e alimento protéico ad libitum. O alimento energético e a água foram fornecidos por orifícios superiores em vidros emborcados com as tampas perfuradas e o alimento protéico em tampas plásticas colocadas na parte inferior das caixas.

O alimento energético fornecido foi o xarope de açúcar invertido na proporção de 1:1. Para a produção do xarope, foram utilizados $5 \mathrm{~kg}$ de açúcar cristal e 5L de água, os quais foram levados ao fogo e, após o início da fervura, adicionaram-se 8 gramas de ácido cítrico, deixando-se o preparado no fogo por mais 45 minutos.

Para a mensuração do índice de mortalidade e do tempo médio de mortalidade, diariamente removiase e anotava-se a quantidade de abelhas mortas em cada caixa, até que todas as operárias tivessem morrido. 
As análises foram realizadas em duas etapas. Na primeira etapa (E01), entre 15 e 30 de janeiro de 2003, foi fornecido para as operárias como alimento protéico: pólen (testemunha positiva, T01); feno de leucena (T02); feno de mandioca (T04) e farinha de bordão-de-velho (T05). Os resultados desses tratamentos foram comparados com os resultados da testemunha negativa, tratamento aprotéico (T03).

Na segunda etapa (E02), entre 07 de julho e 06 de agosto de 2003, além das testemunhas positiva (T01) e negativa (T03), foi fornecido para as abelhas: farelo de babaçu (T02); farinha de algaroba (T04) e sucedâneo do leite (T05).

O pólen apícola utilizado foi adquirido da COOPREPÓLEN, Cooperativa de Pólen do Brasil, localizada na cidade de Canavieiras, Bahia, havendo predominância do pólen de Palmae.

Cada etapa foi composta de cinco tratamentos com três repetições. O índice de mortalidade (IM), expresso em abelhas/dia, foi obtido pela razão entre a quantidade de abelhas mortas e a duração do experimento em dias. O tempo médio de mortalidade (TMM), expresso em dias, foi calculado pela razão entre o somatório das abelhas mortas multiplicado pelo número de dias e o total de abelhas mortas.

A análise dos resultados obtidos foi realizada no programa SAS (1998), por meio de contrastes ortogonais e contrastes de interesse. Foram analisados os mesmos contrastes para as duas etapas do experimento. Os contrastes ortogonais analisados compararam: (T01 + T03) x (T02 + T04 + T05); T01 x T03; (T02 + T04) x T05; T02 x T05. Os contrastes de interesse analisados compararam cada testemunha (positiva e negativa) com os alimentos fornecidos: T01 x T02; T01 x T04; T01 x T05; T03 x T02; T03 x T04; T03 x T05.

\section{RESULTADOS E DISCUSSÃO}

Devido aos altos índices do coeficiente de variação, não foi verificada diferença estatística para os parâmetros estudados tanto em E01 como em E02, ao nível de 5\% de probabilidade. Observa-se, na tabela 1, a análise de variância e as médias de IM e de TMM das duas etapas do experimento de toxicidade. Contudo, pela análise dos contrastes ortogonais, houve diferença significativa entre os alimentos testados na primeira etapa do experimento ( $F=5,53$; $\mathrm{P}<0,05$ ), quando se comparou o TMM das abelhas alimentadas com feno de leucena (T02) e feno de mandioca (T04) contra o TMM de T05, abelhas alimentadas com farinha de bordão-de-velho, (T02 + T04) x T05. A análise dos demais contrastes ortogonais e de interesse demonstrou não existir diferença significativa para os parâmetros estudados.

Embora em E01 tenha sido observada diferença significativa no TMM das abelhas alimentadas com feno de leucena e mandioca (ET02 + T04) e com farinha de bordão-de-velho (T05), como o contraste estudado envolve mais de um tratamento, não foi possível, através desta análise, determinar o que ocorreu entre T02 e T05 ou entre T04 e T05. Contudo, percebe-se na figura 1 que as abelhas alimentadas com farinha de bordão-de-velho apresentaram um aumento de mortalidade a partir do terceiro dia de confinamento, causando uma acentuada declividade na curva de longevidade.

Essa declividade acentuada demonstra uma redução no tempo médio de vida das abelhas alimentadas com farinha de bordão-de-velho, sendo que essas alimentadas morreram aproximadamente dois dias antes que as do tratamento aprotéico (T01), quatro dias antes que as alimentadas com feno de leucena

Tabela 1 - Médias e desvios-padrão do índice de mortalidade (IM) e do tempo médio de mortalidade (TMM) observados nos alimentos testados de 15 a 30 de janeiro de 2003 (E01) e de 07 de julho a 06 de agosto de 2003 (E02), em Teresina, PI.

\begin{tabular}{|c|c|c|c|c|}
\hline \multirow[b]{2}{*}{ Parâmetros } & \multicolumn{2}{|c|}{ E01 ${ }^{1}$} & \multicolumn{2}{|c|}{${\mathrm{E} 02^{2}}^{2}$} \\
\hline & IM (Nºbelhas/dia) & TMM (dia) & $\begin{array}{c}\mathrm{IM}\left(\mathrm{N}^{\mathrm{o}}\right. \\
\text { abelhas/dia) }\end{array}$ & TMM (dia) \\
\hline \multicolumn{5}{|c|}{ Médias e desvios-padrão } \\
\hline T01 & $11,50 \pm 4,68$ & $5,78 \pm 2,27$ & $4,58 \pm 0,86$ & $11,74 \pm 0,76$ \\
\hline T02 & $8,05 \pm 4,35$ & $8,09 \pm 1,87$ & $5,25 \pm 1,39$ & $11,50 \pm 1,82$ \\
\hline T03 & $7,67 \pm 1,50$ & $7,31 \pm 1,20$ & $5,64 \pm 1,90$ & $10,65 \pm 1,80$ \\
\hline T04 & $9,14 \pm 4,83$ & $6,86 \pm 2,48$ & $8,78 \pm 6,60$ & $8,19 \pm 4,29$ \\
\hline T05 & $12,80 \pm 1,61$ & $4,46 \pm 0,45$ & $5,09 \pm 0,38$ & $10,31 \pm 0,68$ \\
\hline
\end{tabular}

1T01: tratamento aprotéico; T02: feno de leucena; T03: pólen; T04: feno de mandioca e T05: farinha de bordão-de-velho.

2T01: tratamento aprotéico; T02: farelo de babaçu; T03: pólen; T04: farinha de algaroba e T05: sucedâneo do leite.

Ciência Rural, v.37, n.2, mar-abr, 2007. 


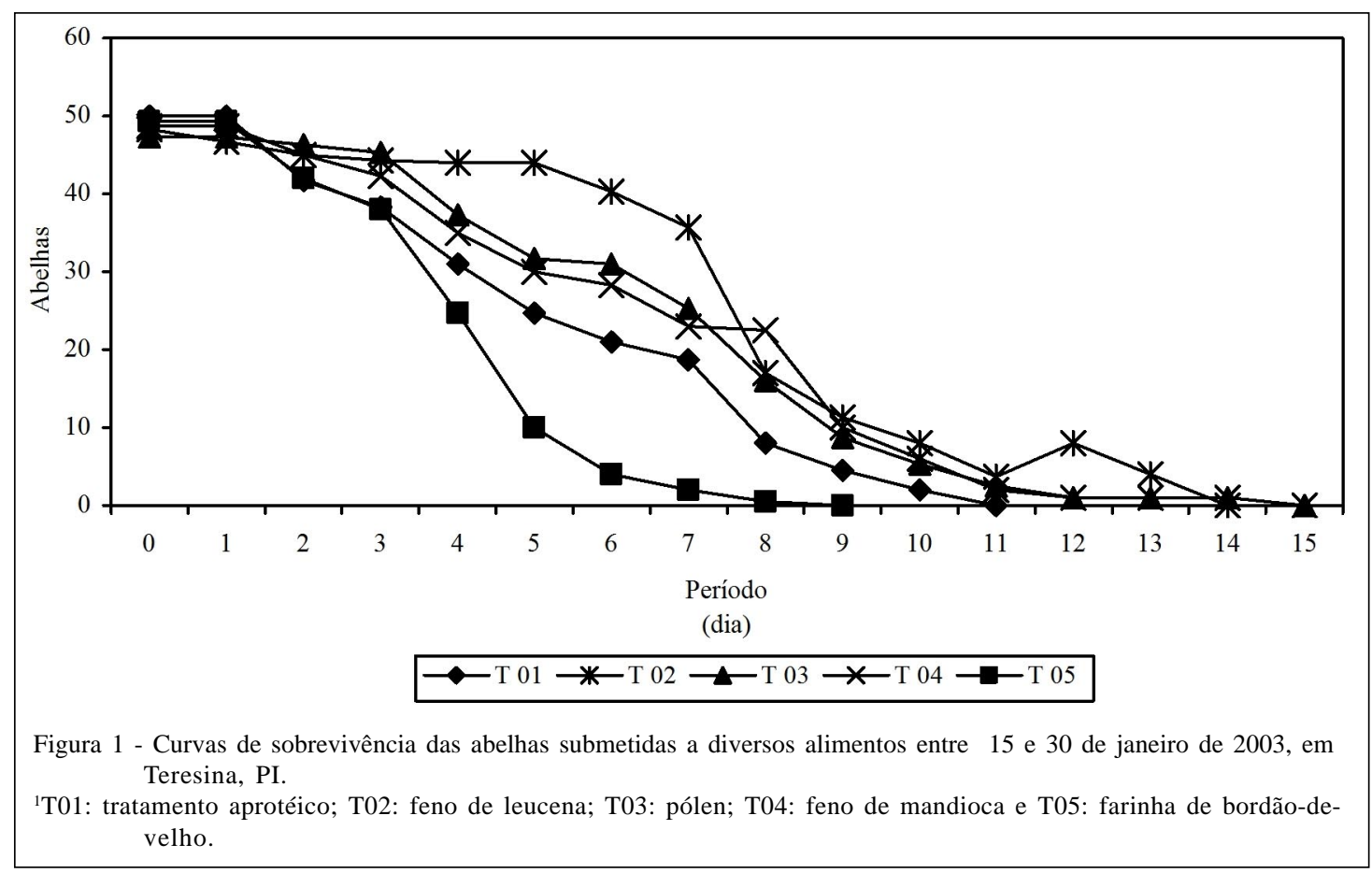

(T02) e seis dias antes que as abelhas alimentadas com pólen (T03) e com feno de mandioca (T04). O IM deste tratamento foi alto, variando de 10,97 a 14,03 abelhas/ dia, e o TMM foi baixo, variando de 4,14 a 4,98 dias. Esses valores evidenciam a baixa longevidade das abelhas alimentadas com a farinha de bordão-de-velho (Pithecellobium cf. saman).

Ao longo do experimento, observou-se que as abelhas pertencentes a T05 morriam envoltas por uma crosta de farinha de bordão-de-velho, possuindo as asas e pernas coladas ao corpo devido ao alimento, enquanto que o mesmo fato não era observado nas abelhas dos demais tratamentos.

Apesar das sementes de bordão-de-velho possuírem um alcalóide tóxico (NASCIMENTO et al., 1996), o tempo de mortalidade das abelhas alimentadas com a farinha desta espécie vegetal pode não estar relacionado ao efeito tóxico do alimento. Aparentemente a alta taxa de açúcar contido na vagem de bordão-de-velho confere à farinha uma propriedade higroscópica e, ao absorver água do meio ambiente, a farinha fica com uma textura muito pegajosa, prejudicando o consumo e grudando no corpo das abelhas, matando-as asfixiadas. Esses resultados demonstram que a farinha de bordão-de-velho não deve ser fornecida às abelhas como única fonte de alimento e que o uso dessa farinha na composição de ração deve ser evitado.
Pela figura 1, observa-se que as abelhas alimentadas com feno de leucena e feno de mandioca tiveram uma longevidade muito similar à longevidade das abelhas alimentadas com pólen. Esses resultados demonstram que o feno dessas espécies não é tóxico para as abelhas e pode ser fornecido como fonte de alimento.

A utilização de feno de mandioca na composição de ração para diversos animais tem sido estudada por outros pesquisadores e seus efeitos tóxicos são conhecidos (PENTEADO \& FLORES, 2000; BOSCOLO et al., 2002). A toxicidade da mandioca é causada por glicosídeos cianogênicos que, ao serem hidrolisados, liberam ácido cianídrico, HCN. Contudo, a desidratação, trituração e moagem da folha de mandioca volatilizam o ácido cianídrico liberado, não causando danos de intoxicação (PENTEADO \& FLORES, 2000) e permitindo o fornecimento das folhas como fonte de alimento.

Os efeitos de toxicidade da leucena em mamíferos devido à presença do aminoácido mimosina têm sido estudados por vários autores, que não aconcelham o fornecimento da leucena como única fonte de alimento, principalmente aos monogástricos (SALVIANO, 1984; VÉLEZ, 1986; VEIGA \& SIMÃO NETO, 1992). Os resultados obtidos neste trabalho contestam esses autores, mostrando que as abelhas Apis mellifera não sentiram os efeitos tóxicos da 
mimosina, podendo-se fornecer o feno de leucena livremente.

A figura 2 ilustra a curva de longevidade das abelhas na segunda etapa do experimento. A declividade acentuada observada na curva de T05 (sucedâneo do leite) a partir do segundo dia é atribuída à alta mortalidade encontrada em uma das repetições. Como posteriormente as abelhas deste tratamento demonstraram maior longevidade, a mortalidade inicial não pode ser atribuída à toxicidade do alimento; é provável que uma fonte de contaminação na gaiola de confinamento tenha provocado essa mortalidade. As abelhas alimentadas com farelo de babaçu tiveram uma longevidade longa, 24 dias, demonstrando que esse alimento é uma alternativa viável como fonte de alimento para as abelhas.

Embora as abelhas alimentadas com farinha de algaroba tenham tido um tempo de vida entre seis e 12 dias a mais que as abelhas submetidas aos demais alimentos, não foi detectada diferença significativa entre os tratamentos. Estudos têm apontado que, ao se fornecer vagem de algaroba em conjunto com melaço de cana-de-açúcar, os glicosídeos cianogênicos da cana-de-açúcar em contato com a emulsina da algaroba causam a formação de ácido cianídrico (HCN) no organismo animal. O HCN inibe as enzimas oxidativas e provoca a morte por asfixia, uma vez que os tecidos deixam de receber oxigênio. Os efeitos podem ser mais drásticos em não-ruminantes (BARBOSA, 1977). Os dados deste experimento sugerem que, para Apis mellifera, a vagem de algaroba pode ser fornecida sem que haja efeito tóxico. RIBEIRO FILHO (1999) considera a algaroba uma ótima alternativa alimentar para as abelhas. Entretanto, recomenda-se evitar o fornecimento das vagens de algaroba com melaço de cana-de-açúcar, enquanto o assunto não for melhor estudado.

Quando se compara a longevidade das abelhas nas duas etapas do trabalho, observa-se que o segundo ensaio, realizado entre 07 de julho e 06 de agosto de 2003, teve um tempo de duração duas vezes maior que o primeiro ensaio, realizado entre 15 e 30 de janeiro de 2003. Essa caracterísitca pode ser observada em especial nos tratamentos aprotéicos das duas etapas (T01 E01 e T01 E02). Segundo Crailsheim (1990) e Crailsheim et al. (1993), em épocas de escassez de alimento, ocorre uma redução da atividade metabólica no organismo das abelhas. A redução no metabolismo pode estar influenciado a longevidade das abelhas no ensaio realizado entre 07 de julho e 06 de agosto de 2003, época em que ocorre escassez de alimento no campo em Teresina.

\section{CONCLUSÃO}

A farinha de bordão-de-velho (Pithecellobium cf. saman) não deve ser fornecida às abelhas Apis mellifera na forma in natura.

O feno de leucena, o feno de mandioca, o farelo de babaçu, a farinha de vagem de algaroba e o

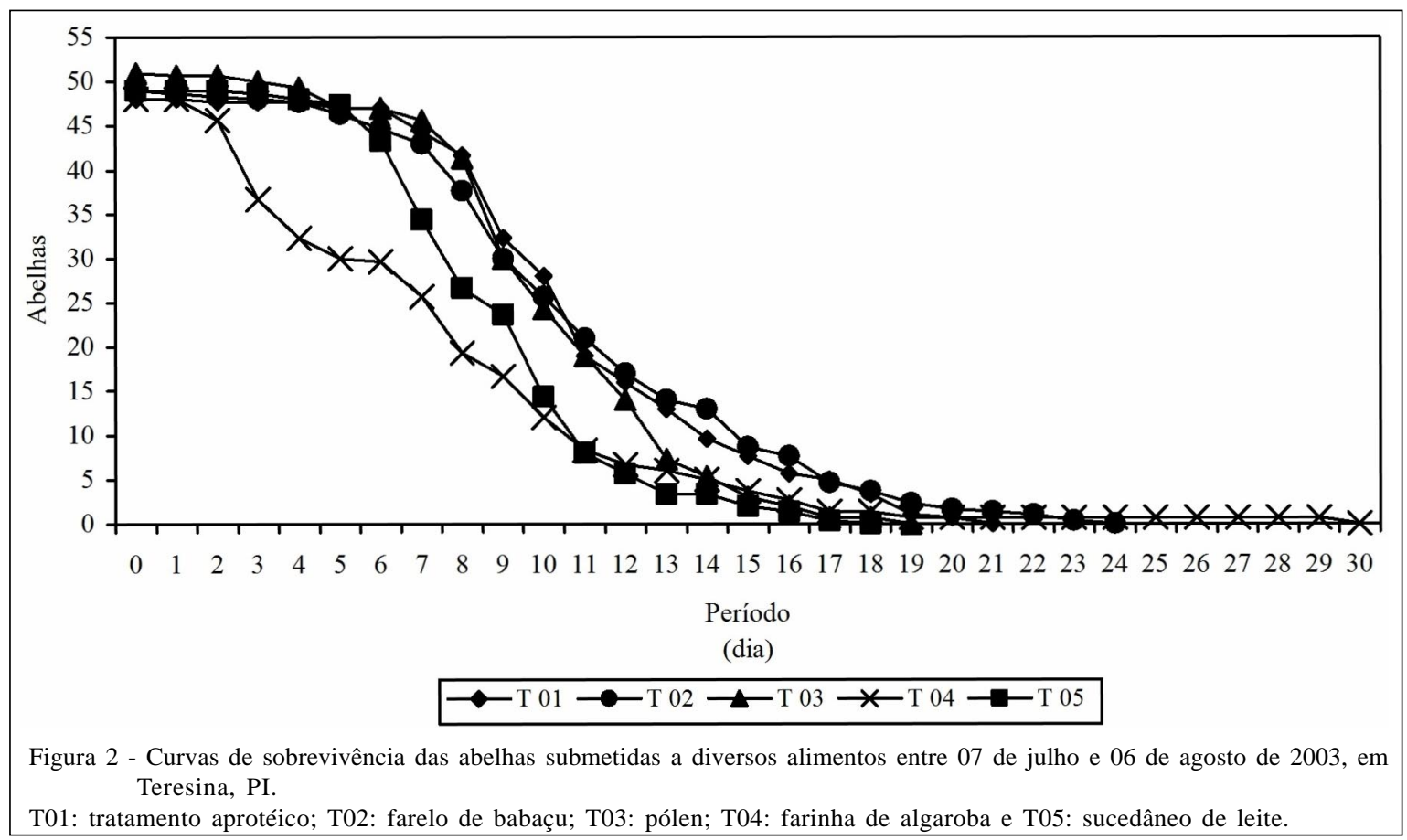

Ciência Rural, v.37, n.2, mar-abr, 2007. 
sucedâneo de leite para bezerros não se mostraram tóxicos para Apis mellifera e podem ser considerados na formulação de rações protéicas para essas abelhas.

\section{AGRADECIMENTOS}

À Financiadora de Estudos e Projetos (FINEP), pelo apoio financeiro; ao Conselho Nacional de Pesquisa (CNPq), pela consessão das bolsas; à Fundação de Amparo a Pesquisa do Estado do Piauí (FAPEPI), à Embrapa Meio-Norte e à Universidade Federal do Ceará (UFC), pelo apoio institucional; e aos Profs. David de Jong e Zilá Luz Paulino Simões, pelas valiosas sugestões.

\section{REFERÊNCIAS}

BARBOSA, H.P. Valor nutritivo da algaroba (Prosopis juliflora (Sw) D.C.) através do ensaio da digestibilidade em carneiros. 1977. 48f. Dissertação (Mestrado em Zootecnia) - Curso de Pós-graduação em Zootecnia, Universidade Federal de Viçosa.

BARKER, R.J. Some carbohydrates found in pollen and pllen substitutes are toxic to honey bees. Journal of Nutrition, Bethesda, v.107, n.10, p.1859-1862, 1977.

BOSCOLO, W.G. et al. Farinha de varredura de mandioca (Manihot esculenta) na alimentação de alevinos de tilápia do nilo (Oreochromis niloticus L.). Revista Brasileira de Zootecnia, Viçosa, v.31, n.2, p.546-551, 2002.

CEPRO (Piauí:Brasil). Perfil dos municípios piauienses. Teresina: CEPRO / Governo do Estado do Piauí, 1992. 590p.

CRAILSHEIM, K. The protein balance of the honey bee worker. Apidologie, Avignon, n.21, p.417-429, 1990.

CRAILSHEIM, K. et al. Pollen utilization in non-breeding honeybees in winter. Journal of Insect Physiology, v.39, n.5, p.396-373, 1993.

FREITAS, B.M. Potencial da caatinga para a produção de pólen e néctar para exploração apícola. 1991. $140 \mathrm{f}$. Dissertação (Mestrado em Zootecnia) - Curso de Pós-graduação em Zootecnia, Universidade Federal do Ceará.

HAYDAK, M.H. Value of pollen substitutes for brood rearing of honeybees. Journal of Economic Entomology, v.38, n.4, p.484-487, 1945.

KULINCEVIK, J.M.; ROTHENBUHLER, W.C. Laboratory and field measurements of hoarding behavior in the honeybee. Journal of Apicultural Research, v.12, n.3, p.179-182, 1972.

LIMA A. O.N. Pólen coletado por abelhas africanizadas em apiário comercial na caatinga cearense. 1995. 118f. Dissertação (Mestrado em Zootecnia) - Curso de Pós-graduação em Zootecnia, Universidade Federal do Ceará.
NASCIMENTO, M.P.S.C.B. et al. Forrageira da bacia do Parnaíba: usos e composição química. Teresina: Embrapa, Recife: Associação Plantas do Nordeste, 1996. 86p.

PENTEADO, M.V.C.; FLORES, C.I.B. Folhas da mandioca como fonte de nutrientes. In: CEREDA, M.P. (Coord). Culturas de tuberosas amiláceas latino americanas. Volume 4 - manejo, uso e tratamento de subprodutos da industrialização da mandioca. São Paulo: Fundação Cargil, SP, 2000. Capturado em 15 jan. 2005. Online. Disponível em: www/raízes-ong.org.br/portugues/indexpor.htm.

PEREIRA, F.M. Alimentação das colmeias. In: SEMINÁRIO PIAUIENSE DE APICULTURA, 5., 1997, Teresina, PI. Anais... Teresina: BN/FEAPI/Embrapa Meio-Norte,1997. 92p. p.21-26.

PEREIRA, F.M. Gargalos tecnológicos. In: VILELA, S.L.O.; PEREIRA, F.M. Cadeia produtiva do mel no estado do Rio Grande do Norte. Natal: SEBRAE-RN; Teresina: Embrapa Meio-Norte, 2002. Cap.3, p.66-92.

PEREIRA, F.M. et al. Gargalos tecnológicos e não-tecnológicos. In: VILELA, S.L.O.; ALCOFORADO FILHO, F.G. (Org). Cadeia produtiva do mel no estado do Piaú. Teresina: Embrapa Meio-Norte, 2000. Cap.2, p.30-47.

SAS INSTITUTE INC. SAS/STAT User's guide-version 6. 4.ed. Cary, NC, 1989. V.2, 846p.

RIBEIRO FILHO, F.C. Alternativas para alimentação na entressafra. In: SEMINÁRIO PIAUIENSE DE APICULTURA, 6., 1999, São Raimundo Nonato, PI. Anais... São Raimundo Nonato: BN/FEAPI/SEBRAE/Embrapa Meio-Norte/Prefeitura de São Raimund Nonato/SEABB, 1999. 80p, p.37-43.

SALVIANO, L.M.C. Leucena: fonte de proteínas para os rebanhos. Petrolina, Embrapa-CPATSA, 1984. 16p. (Circular Técnica, 11).

SOUSA, R.M. et al. Variações na população silvestre da abelha africanizada (Apis mellifera L.) na caatinga. In: ENCONTRO SOBRE ABELHAS, 4., 2000, Ribeirão Preto, SP. Anais... Ribeirão Preto, SP: Universidade de São Paulo, Faculdade de Filosofia, Ciências e Letras, Ribeirão Preto, 2000. 363p. p.295.

SYLVESTER, H.A. Honey bees: response to galactose and lactose incorporeted into sucrose syrup. Journal of Economic Entomology, n.72, p.81-82, 1979.

VEIGA, J.B.; SIMÃO NETO, M. Leucena na alimentação animal. Belém:Embrapa-CPATU, 1992. 4p. (Recomendções Básicas, 19).

VELEZ, C.E.S. Rendimento, valor nutritivo e toxicidade de feno de leucena em ovinos. 1986. 77f. Dissertação (Mestrado em Zootecnia). - Curso de Pós-graduação em Zootecnia, Escola de Veterinária, Universidade Federal de Minas Gerais. 